\title{
PATENTS
}

\section{How does emerging patent case law in the US and Europe affect precision medicine?}

\author{
Mateo Aboy, Kathleen Liddell, Cristina Crespo, Glenn Cohen, Johnathon Liddicoat, Sara Gerke \& Timo Minssen \\ An analysis of how today's patent law will affect tomorrow's innovation in three areas of precision medicine: (1) \\ biomarkers and nature-based products; (2) diagnostics; and (3) algorithms, big data, and AI.
}

No topic in medicine garners more interest today than precision medicine, with its goal of better tailoring treatment to patient needs. It is not only patients who stand to benefit from better diagnosis, prognosis and treatment, but also the organizations investing in its research and development ${ }^{1}$. According to one recent estimate, the global precision medicine market accounted for $\$ 43.59$ billion in 2016 and is expected to reach $\$ 141.70$ billion by 2026 with a compound annual growth rate of $11.23 \%$ between 2017 and $2026^{2}$.

The commercial viability, and hence development, of precision medicine depends in large part on the intellectual property framework that applies to its various forms. In this paper we examine recent patent law decisions in the U.S. and Europe and their implications for the future of three areas of precision medicine: (1) biomarkers and nature-based

\footnotetext{
Mateo Aboy, Cristina Crespo, Kathleen Liddell, Johnathon Liddicoat - Centre for Law, Medicine, and Life Sciences (LML), Faculty of Law, University of Cambridge, Cambridge, UK. Timo Minssen - Center for Advanced Studies in Biomedical Innovation Law (CeBIL), University of Copenhagen. Glenn Cohen and Sara Gerke Harvard Law School. Corresponding Author Email:ma608@.cam.ac.uk
}

products; (2) diagnostics; and (3) algorithms and AI.

Understanding the three "Precision Medicine" Categories

Before discussing how patent law treats these categories, it is useful to be more specific about each.

A biomarker is "a defined characteristic that is measured as an indicator of normal biological processes, pathogenic processes, or responses to an exposure or intervention, including therapeutic interventions. Molecular, histologic, radiographic, or physiologic characteristics are types of biomarkers" (FDA/NIH BEST) ${ }^{3}$. Examples include a genetic sequence or a hormone level. With suitable knowledge, comparing a biomarker with a baseline measurement enables one to predict or diagnose a disease state, or choose a better treatment or drug dosage. Identifying biomarkers relevant at a population level is the first challenge, but even more difficult is to validate biomarkers that are sufficiently accurate and precise to be clinically useful in individual patients. To date, a large number of potential biomarkers have been identified but very few have been qualified by the FDA for use in clinical trials or entered the clinic as diagnostic tools ${ }^{4}$. Considerable $\mathrm{R} \& \mathrm{D}$ is still required, with associated expense and risk. The FDA/NIH BEST Biomarkers, Endpoints, and other Tools) Resource provides examples for each category of biomarkers, including diagnostic, monitoring, pharmacodynamic/ response, predictive, and prognostic biomarkers $^{3}$. As an example, the Oncotype DX is a test based on a biomarker which assists doctors in determining proper cancer treatment 5 .

Precision medicine also builds on understandings of relationships and correlations. This requires domain knowledge and judgement of the various inputs, outputs, and their interaction. To develop clinical-grade biomarkers based on relationships and correlations requires significant $\mathrm{R} \& \mathrm{D}$, as well as scientific validation and regulatory approval or qualification. Natural relationships, correlations and algorithms can be used to develop digital biomarkers from quantifiable physiological or behavioral data collected by means of digital devices such as portables, s martphones, wearables, implantables or digestibles to explain, guide or predict healthrelated outcomes. One example involves measurement of gait and balance using wearable technologies to develop monitoring, prognostic or therapy response biomarkers, which can be used to assess 
progression of neurological dysfunction in Parkinson's disease and other movement disorders ${ }^{6}$.

Algorithms, big data, and artificial intelligence (AI) in medicine can help examine vast amounts of health data, such as the results of diagnostic tests, physiologic signals, or patient biomarkers, in order to make predictions and recommendations tailored to the characteristics of a patient. Some AI operates using "black box" algorithms, in the sense that some aspects of machine-learning are not explicitly articulated, because AI results can be generated based on implicit correlations within the data, as opposed to following a sequence of specified steps or using fundamental, well-understood correlations based on domain knowledge. In truth it is better to think of this as a spectrum of "opacity" of the "box"7. Medical correlations often reflect complex interactions of natural relationships at an individual or group level, rather than universal natural laws such as $\mathrm{E}=\mathrm{mc}^{2}$. For instance, the Oncotype DX test is considerably more specific and correlates various biomarkers to create a cancer Recurrence Score ${ }^{5}$.

Starting first with the US followed by Europe, we examine how patent law developments in the areas of nature-based products (product biomarkers), correlations, algorithms, and their underlying logic affect each of these areas of precision medicine.

\section{Emerging US Case Law}

\section{A. Biomarkers \& Correlations}

In 2012, the US Supreme Court held in Mayo Collaborative Services $v$ Prometheus Laboratories (Mayo) that Prometheus' patents set forth laws of nature and were therefore not patentable8. The patent claim at issue involved the relationship between metabolite concentrations in blood and medical predictions whether a dosage of a thiopurine drug will prove ineffective or cause harm. A year later, in 2013, the US Supreme Court held in $A M P v$ Myriad Genetics (Myriad) that "[a] naturally occurring DNA segment is a product of nature and not patent eligible merely because it has been isolated, but cDNA is patent eligible because it is not naturally occurring"'.

These two US decisions have been controversial, and criticised by many commentators for undermining innovation incentives in precision medicine ${ }^{10,11}$. Some groups have been seeking Congressional action ${ }^{12}$. As of now, the boundaries of patent eligibility remain those set by the Supreme Court, which have been interpreted and applied by the US patent office (USPTO) and lower courts. To understand fully the implications of the Supreme Court cases for precision medicine, one must take account of the nuance in the judges' reasoning.

The Court held in Mayo that "if a law of nature is not patentable, then neither is a process reciting a law of nature, unless that process has additional features that provide practical assurance that the process is more than a drafting effort designed to monopolize the law of nature itself"8. Thus in order to transform an ineligible law of nature into a patent-eligible application, a patent must do more than simply state the law of nature while adding the words "apply it." The patent must limit its reach to a particular, inventive application of the law. The Court's opinion was that, besides simply describing the natural relationship between concentrations of thiopurine metabolites and optimum dosage, Prometheus' patent claim did not go beyond "well-understood, routine, conventional activity, previously engaged in by those in the field"8 because clinicians had previously tailored dosages of thiopurine drugs for individual patients). In essence, the claims were directed to the natural law itself.

\section{B. Algorithms}

Turning to the patentability of algorithms and computerimplemented inventions, the US Supreme Court held in Alice Corp v CLS Bank International (Alice) in 2014 that "merely requiring generic computer implementation fails to transform [an] abstract idea into a patent-eligible invention"13. The patent claimed a method for exchanging financial obligations (the process of financial settlement) using a third-party intermediary, and the computer system to carry out the method. The Supreme Court held the patent was ineligible, applying the two-step test developed in Mayo. First, determine whether the claims are 'directed to' an abstract idea (Step 2A). If so, consider whether additional claim elements which, individually or as an ordered combination, amount to 'significantly more' than the abstract idea (Step 2B). That is, ascertain the presence of an 'inventive concept' which transforms the abstract idea into a patent-eligible invention. The Court concluded the claims were directed to the abstract idea of using a neutral intermediary to reduce risk during the settlement process, and that merely implementing the idea through a computer did not add anything of substance to the claims that would amount to an inventive concept.'

Alice followed several earlier cases, including Bilski v Kappos ${ }^{14}$ where the abstract idea of risk hedging, a "fundamental economic practice," was ineligible and using a computer to implement the algorithm did not change that.

\section{Underlying Concern}

In all of these cases the Supreme Court's concern was to exclude patent applications that unduly 'pre- 


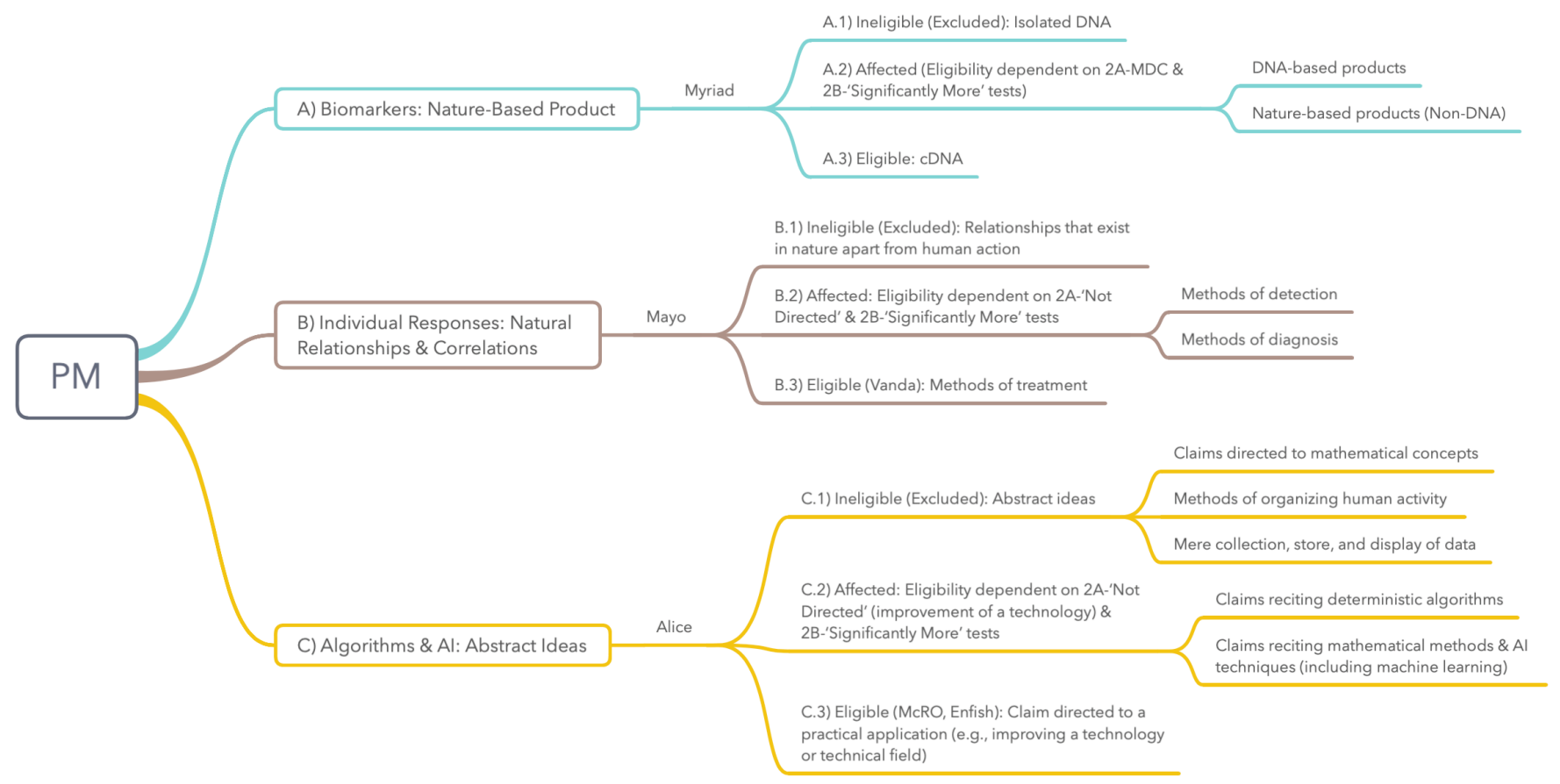

Figure 1 Application and impact of emergent patent case law to different categories of precision medicine, including biomarkers, diagnostics, and algorithms/AI.

empt' future innovation by effectively tying up the underlying 'abstract idea', 'natural law' or 'natural phenomena' (including products of nature), albeit for the limited duration of the patent. But the Court made clear that an invention is not ineligible for patent protection simply for involving an abstract concept or a natural law. Applications of an abstract concept (or natural phenomena) "to a new and useful end"13 or to solve a technological problem, even in "conventional industry practice" 15 , are patent eligible.

This nuance can also be seen in an earlier case involving medical device technology, In re Abele ${ }^{16}$. The patent concerned the invention of a tomographic scanner. Some claims were found ineligible as they were directed to the algorithm per se ("the algorithm is neither explicitly nor implicitly applied to any certain process"16), whereas other claims were eligible as they were directed to the technical application of the algorithm, resulting in "an improved CAT-scan process." 16 The improvement resided "in the application of a mathematical formula within the context of a process which encompasses significantly more than the algorithm alone."16

The Supreme Court's view is that pre- or post-solution activities included in a claim (i.e., activities incidental, nominal or tangential to the primary process or product) should be scrutinised carefully to assess whether the claims genuinely amount to 'significantly more' than ineligible subject matter. After all, a "competent draftsman could attach some form of post-solution activity to almost any [abstract idea or natural phenomenon]" (MPEP $\$ 2016.05(\mathrm{~g}))$. Crafty drafting should not be allowed to mask pre-emptive claims. Otherwise, for instance, extra-solution activity such as data gathering before performing a clinical test, or determining the level of a biomarker in the blood ${ }^{8}$, or assessing the meaning of a biological test measurement could mask an unduly pre-emptive claim and allow the patent to tie up a natural relationship.

Impact on Precision Medicine The cases of Myriad, Mayo, and Alice affect the patent eligibility of all three broad categories of inventions in precision medicine, namely those involving: 1) biomarkers and naturebased products (Myriad), 2) relationships and correlations (Mayo), and 3) algorithms and AI (Alice).

Figure 1 shows a summary of how these US cases apply to the three categories of precision medicine, as well as the patent eligibility status of various types of inventions within each of these groups.

Notably, patent subject-matter eligibility (35 USC \$101) is just one of several criteria that the patent application must meet. The invention must also be novel (35 
USC \$102), non-obvious (35 USC $\$ 103)$ and appropriately disclosed (35 USC \$112). While the initial requirement of subject-matter eligibility for precision medicine inventions is the focus of this article, inventions that meet this hurdle can still be rejected based on other criteria, such as not being novel or non-obvious in light of prior art.

In the immediate aftermath of Myriad, Mayo and Alice there was a high degree of uncertainty as to their impact on precision medicine. For example, would Myriad affect biomarker patents other than isolated DNA? Given that precision medicine can rely on individual responses to particular treatment, would Mayo's exclusion of relationships and correlations that exist "in principle apart from human action" drastically limit patent protection in this field? Would the abstract idea exclusion developed in Alice affect the eligibility of algorithms for precision medicine?

Having the benefit of the latest USPTO Examination Guidance (MPEP 2106 and January 2019 Examination Guidance Update ${ }^{17}$ ), additional decided cases, and empirical studies $18,19,20,21$, it is timely to assess the current state of patent eligibility for precision medicine.

\section{A) Biomarkers \& Nature-Based Products}

In the case of Myriad, although the decision was predicted by some legal scholars to be a 'surgical strike', merely excluding isolated genomic DNA from patent eligibility 22 (Figure 1 Type A.1), the case has had broader impact ${ }^{20}$. In fact, our prior research estimated that when Myriad was cited by examiners as grounds for a 35 USC 101 rejection, $85 \%$ of the cases concern naturebased product patent claims beyond isolated DNA20. The explanation is that, over time, the USPTO and lower courts have interpreted Myriad as a general product of nature case and reconciled it with the two-step test adopted in Mayo/Alice. Thus the product of nature exclusion presently affects patent claims that 'recite' a nature-based product (Step A), except if the nature-based product is 'markedly different' from a naturally-occurring product or if the claim includes 'significantly more' (Step B). Accordingly, the product of nature exclusion narrows product claims in relation to a wide variety of nature-based biomarkers (e.g., proteins, RNA, hormones) ${ }^{20}$.

Our previous research also found that it has not been easy to draft around Myriad. In more than $70 \%$ of the patent applications examined in the 3 years after Myriad, applicants responded by cancelling the isolated DNA claims or abandoning their applications ${ }^{19}$.

However, although a broad variety of precision medicine biomarkers are harder to patent since Myriad, it is not impossible. The Supreme Court confirmed that cDNA is patentable (provided it is long enough to be structurally different from naturally occurring gDNA) (Figure 1 type A.3). Furthermore, our previous research indicates that approximately $48 \%$ of patent applications have managed to advance to allowance after receiving a Myriad-based rejection ${ }^{19}$. Besides claiming cDNA, there are at least eight types of amendments that have transformed ineligible subject matter into patent eligible claims (passing the 'markedly different characteristics' or 'significantly more' tests (Figure 1 type A.2) $)^{19}$.

\section{B) Individual Responses \& Methods of Diagnosis: Natural Relationships \& Correlations}

The trio of Supreme Court cases has had a particularly strong impact on precision medicine inventions that rely on relationships and correlations to diagnose or target treatment to patients. But the proverbial pendulum appears to be swinging back. How far is presently unclear.

To appreciate the impact, it is useful to sub-categorize invention claims as follows: 1) methods directed to the underlying relationships of human response (these are ineligible), 2) methods of detection or methods of diagnosis (affected by the case law; eligibility depends on closer analysis of claims), and 3) methods of treatment (eligible) (Figure $\mathbf{1}$ category B). These sub-categories concern patent claims directed at methods, but may also involve, inter alia, diagnostic, prognostic, and predictive biomarkers.

As mentioned, in Mayo, the US Supreme Court rejected the eligibility of a method to optimize the dosage of a thiopurine drug relying on a relationship between measured levels of thiopurine metabolite and patient response. The Court held the relationship exists in principle without human action (Figure 1 type B.1).

The Court of Appeals for the Federal Circuit reached a similar conclusion in Sequenom in 201523. A patent concerning non-invasive prenatal testing, with potentially significant implications for screening embryos and foetuses for genetic conditions $^{24}$, was ineligible for US patent protection. The court concluded the patent set forth a platform for detecting the natural phenomenon of fetal DNA circulating in the mother's blood and did not offer significantly moreonly non-inventive applications of circulating fetal DNA in diagnosing well-known genetic disorders such as Down's Syndrome (Figure 1 type B.1).

A clear sign of a less restrictive interpretation of Mayo emerged with the decision of the Court of Appeals for the 2018 Federal Circuit in Vanda ${ }^{25}$. The softening in the 
Court's decision hinged on the patent claim being interpreted as a method of treatment claim (Figure 1 type B.3). The Court held that method of treatment claims involve human intervention; accordingly the invention is not directed to a natural relationship itself and consequently is not directed to an ineligible law of nature or natural phenomena.

The reasoning in Vanda indicated it will be significantly easier to prosecute a method of treatment claim than methods of detection or diagnosis, even though to some extent all involve natural relationships between the human body and something else. Since a method of treatment claim is prima facie held 'not directed to' an ineligible law of nature, the patent applicant does not have to marshal arguments to show that the application involves 'significantly more' than a law of nature. Drafting the claim as a method of medical treatment claim circumvents Step 2 of the Mayo test.

In contrast, precision medicine innovations that hinge on a method of detection or diagnosis typically have to contend with step 2 of the Mayo/Alice test (Figure 1 type B.2). Of these, methods of detection generally have better odds of satisfying Steps $2 \mathrm{~A}$ or $2 \mathrm{~B}$ of the Mayo/Alice test, provided they employ unconventional/non-routine techniques.

Inventions with claims merely directed to methods of diagnosis (i.e., those without further human action in the form of a treatment) are likely the most difficult to patent post-Mayo.

While the Mayo decision has been highly controversial, with some arguing it would be disastrous for meritorious inventions in the life sciences, biotech and precision medicine 26,27 , recent empirical studies show that in approximately
$35 \%$ of the cases applicants have been able to overcome Mayo-based rejections ${ }^{21}$. It should be noted, however, that since Mayo there has a been a high degree of uncertainty regarding eligible and ineligible inventions. As a consequence, patent applications in the field of precision medicine are rejected at a relatively high frequency for failing to satisfy the patent eligibility test of 35 USC $\$ 101$. In previous research we estimated an increase in the numbers of patent applications receiving a $\$ 101$ rejection rising from $10.5 \%$ to $55 \%$ in the 6 years following Mayo (Art Unit 1634). We also found that there was a significant increase in the time and expense involved in prosecuting a precision medicine patent ${ }^{21}$. After Vanda, it is expected that, where possible, patent attorneys may use claim constructions that more closely approximate methods of treatment (Figure 1 type B.3), and the rejection rate where examiners cite \101 with Mayo will subside to some extent.

In summary, it is still possible (provided claims are carefully drafted and/or constructed as method of treatment claims) but currently challenging, to obtain broad US patent protection for precision medicine inventions that rely on relationships and correlations.

\section{C) Algorithms and AI}

While Alice is often considered a decision that affects primarily the patentability of business methods and generic abstract ideas, the decision also affects computerimplemented inventions in general, and therefore precision medicine inventions based on algorithms and AI.

It is possible to distinguish three types of precision medicine inventions in this category, namely, those that have been explicitly excluded from patent protection, those which are not categorically excluded but affected by legal developments, and those whose eligibility has been established by recent case law or specific examination guidance (Figure 1 category $\mathrm{C}$ ).

Within the ineligible category (Figure 1 type C.1), one finds inventions directed to mathematical algorithms and mathematical concepts. It is also likely that precision medicine inventions directed to methods of patient engagement (participative care) may be ineligible, on the basis that they are methods of organizing human activity or concepts related to managing human behavior (MPEP 2106). Similarly, expert medical systems applying specialist domain knowledge to diagnose like a human doctor may be deemed ineligible as "concepts relating to organizing or analyzing information in a way that can be performed mentally or is analogous to human mental work" (MPEP 2106). This exclusion also applies to precision medicine inventions claimed at a high level of generality, such as the method for diagnosing an abnormal condition by performing clinical tests and analyzing the results in In re Grams ${ }^{28}$.

A significant proportion of precision medicine inventions affected by Alice (Figure 1 type C.2) are based on algorithms that analyze patient data (including physiological signals) in order to develop biomarkers which can be used to diagnose or guide individualized treatment. Such algorithms can be deterministic, statistical, or based on artificial intelligence techniques. While all these algorithms are fundamentally different from a technical standpoint, most of them make use of mathematical equations, mathematical algorithms, and digital signal processing in some form. Accordingly, it is often the 
case that examiners conservatively issue $\$ 101$ Alice-based rejections on the basis that the claimed invention 'recites' mathematics and algorithms. Furthermore, the inventive concept often lies in the algorithm itself and not the hardware (e.g., a new algorithm that can be implemented in any computing device such as a smartphone and processes physiologic signals acquired using standard sensors).

The key to eligibility for these inventions lies in whether the claims satisfy the Mayo/Alice test. Recognizing the level of legal uncertainty surrounding this framework, in its most recent update, the USPTO amended the test to help identify ineligible claims more accurately and consistently (USPTO Eligibility Guidance, Jan 2019 Update ${ }^{17}$ ). Step 2A, which consists of identifying whether a claim is 'directed to' an abstract idea, now takes a two-prong approach, first asking whether the claim 'recites' an abstract idea (e.g., mathematical concept, method of organising human activity, or mental process), and if so, whether the claim as a whole incorporates the abstract idea into a 'practical application.' Contrary to previous guidance and practice, examiners are now instructed to give weight to all elements of the claim when assessing practical application, whether or not they are conventional. The 'significantly more' inquiry of Step 2B is where the additional elements of the claim are examined to identify an inventive concept beyond well understood, routine, or conventional activity. According to the USPTO this approach should yield the same eligibility outcome as the original method, albeit maybe at different steps in the Mayo/Alice test.

Similar to the effect of Vanda on methods of treatment, the new USPTO guidelines open a window for precision medicine inventions

\section{Box 1 Notable Post-Alice Cases FairWarning, McRO, Enfish}

In FairWarning IP, LLC v Iatric Systems, Inc. ${ }^{33}$, the Federal Circuit found a method and system of detecting improper access of a patient's protected health information in a computer environment ineligible as being directed to an abstract idea. The Federal Circuit explained that the claimed invention did no more than collect information regarding user access to health records, analyzing this log data based on a set of rules, and providing notification if improper access is detected.

The Court likened these claims to those in Alice, where the claimed invention essentially amounts to using a computer to automate a process previously being performed by humans. The idea that this produced an improvement in a technology field by increasing speed was rejected, as the improved efficiency arises "from the capabilities of a general-purpose computer, rather than the claimed method." The Court reasoned that in this case, as in Alice, "it is [the] incorporation of a computer, not the claimed rule, that purportedly improves the existing technological process."

In the FairWarning decision, the Federal Circuit stressed the difference between the claims at hand and those in the previously decided cases of $M c R O^{31}$ and Enfish ${ }^{32}$. The
McRO patent claimed a computer automated method for animating lip synchronization and facial expression of 3D characters. Although, like in FairWarning, the method involved the use of specific rules to automate a task previously performed by humans, the Court emphasized that in the case of $M c R O$ the claimed invention transformed a process traditionally based on subjective rules performed by human animators into a set of specific mathematical rules that allowed implementation in a computer. Therefore, "it [was] the incorporation of the claimed rules, not the use of the computer, that 'improved [the] existing technological process"," and thus constituted an improvement in the technology field of computer animation.

The claims in Enfish were directed to a selfreferential table for a computer database. Despite being defined in terms of logical structures with no physical components, the Federal Circuit found the Enfish claims to be "directed to a specific implementation of a solution to a problem in the software arts, and thus $[\ldots]$ not directed to an abstract idea," but rather an improvement in computer technology. The Federal Circuit pointed to the difference between the focus of the claims being "on an improvement in computers as tools" (Enfish) as opposed to "an abstract idea using computers as tools" (FairWarning). involving algorithms implemented in standard hardware to satisfy the Mayo/Alice test at Step 2A, circumventing the 'significantly more' inquiry, by integrating the algorithm into a practical application. The courts have indicated that some elements do not confer practical application, including mere computer implementation of an otherwise ineligible abstract idea (Benson ${ }^{29}$ ); addition of insignificant extrasolution activity such as gathering input data or outputting results, when these are merely a nominal or tangential addition to the claim (Flook $\left.{ }^{30}\right)$; nor generally linking the abstract idea to a particular technological environment (Bilski14). Conversely, examples of elements that have been considered valid 'practical applications' include: (1) improvement to a technology or technical field, (2) application of the algorithm to effect a particular treatment or prophylaxis for a disease or medical condition, and (3) use of a particular machine or manufacture that is integral to the claim, or (4) transformation of a particular article to a different state or thing. The recent cases of McRO31, Enfish ${ }^{32}$ and FairWarning IP, LLC v. Iatric Systems, Inc. ${ }^{33}$ (Box 1) provide a good illustration of these concepts.

In situations where a precision medicine invention can be implemented using standard hardware (standard processors, standard sensors, standard patient monitors, etc) and the inventive concept lies primarily with the novel algorithm or the specific application of AI techniques to solve a particular problem, the claim 
Table 1 Comparison of US and European patent subject-matter eligibility of precision medicine inventions.

\begin{tabular}{|c|c|c|c|}
\hline $\begin{array}{l}\text { PATENT ELIGIBILITY } \\
\text { COMPARISON }\end{array}$ & CLAIM DIRECTED TO & US & Europe \\
\hline \multirow{3}{*}{$\begin{array}{c}\text { Precision medicine } \\
\text { inventions based on } \\
\text { Nature-Based Products }\end{array}$} & Isolated DNA & $\begin{array}{l}\text { NO }(\text { Myriad }) \\
\text { Natural Phenomena Exclusion }\end{array}$ & $\begin{array}{c}\text { YES } \\
\text { (EPC Art. } 52(2) \& 52(3) ; \text { R. 26,27,29) }\end{array}$ \\
\hline & cDNA & YES (Myriad) & $\begin{array}{c}\text { YES } \\
\text { (EPC Art. 52(2) \& 52(3); R. 26,27,29) }\end{array}$ \\
\hline & Other natured-based products & $\begin{array}{l}\text { Only if 'markedly different' or claim includes } \\
\text { 'significantly more' }\end{array}$ & $\begin{array}{c}\text { YES } \\
\text { (EPC Art. 52(2) \& 52(3); R. 26,27,29) }\end{array}$ \\
\hline \multirow{4}{*}{$\begin{array}{c}\text { Precision medicine } \\
\text { inventions based on } \\
\text { Individual Responses } \boldsymbol{\&} \\
\text { Correlations }\end{array}$} & Responses \& Correlations & $\begin{array}{l}\text { NO (Majo, Ariosa/ Sequenom) } \\
\text { Law of Nature Exclusion }\end{array}$ & $\begin{array}{l}\text { YES (Illumina, Sequenom) } \\
\text { Technical character conferred by technical } \\
\text { application in precision medicine }\end{array}$ \\
\hline & Methods of Detection & $\begin{array}{l}\text { Only if 'not directed' to a law of nature or claim } \\
\text { includes 'significantly more' }\end{array}$ & $\begin{array}{l}\text { YES (Illuminina, Sequenom) } \\
\text { Technical chatacter conferred by technical } \\
\text { application in precision medicine }\end{array}$ \\
\hline & Methods of Treatment & YES (Vanda) & $\begin{array}{l}\text { Only if claim avoids EPC Art. } 53(c) \text { exclusion, } \\
\text { either as dosage regimes and/or new medical } \\
\text { indications (e.g., for a particular patient }\end{array}$ \\
\hline & Method of Diagnosis & $\begin{array}{l}\text { Only if 'not directed' to a law of nature or claim } \\
\text { includes 'significantly more' }\end{array}$ & $\begin{array}{l}\text { YES (if method of in-vitro diagnosis does not fall } \\
\text { under the Art 53(c) exclusion) }\end{array}$ \\
\hline \multirow{3}{*}{$\begin{array}{l}\text { Precision medicine } \\
\text { inventions based on } \\
\text { Algorithms }\end{array}$} & $\begin{array}{l}\text { Pure Mathematical Methods or } \\
\text { Algorithms (including AI) as such }\end{array}$ & $\begin{array}{l}\text { NO (Alice) } \\
\text { Abstract idea exclusion }\end{array}$ & $\begin{array}{c}\text { NO } \\
\text { EPC Art. 52(2) Exclusion; } \\
\text { Devoid of 'technical character' }\end{array}$ \\
\hline & $\begin{array}{l}\text { Mathematical Methods or Algorithms } \\
\text { (including AI) implemented in a computer or device }\end{array}$ & $\begin{array}{l}\text { NO }(\text { Alice }) \\
\text { Abstract idea exclusion, mere computer } \\
\text { implementation is not enough }\end{array}$ & 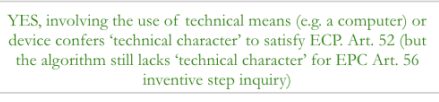 \\
\hline & $\begin{array}{l}\text { Mathematical Methods or Algorithms } \\
\text { (including AI) directed to a technical } \\
\text { application or sperific tecbnical implementation }\end{array}$ & $\begin{array}{l}\text { Yes, (McRO ¿ Enflisb), claim not directed to the abstract } \\
\text { idea itself but it to a practical application (e.g. } \\
\text { improvement of a technology or technical field) }\end{array}$ & $\begin{array}{l}\text { YES, 'technical application' or specific 'technical } \\
\text { implementation' confers 'technical character' to the } \\
\text { algorithm for the purposes of EPC Art. } 52 \& 56\end{array}$ \\
\hline
\end{tabular}

drafting and prosecution strategies most likely to be successful are those which satisfy the Alice eligibility test at Step $2 \mathrm{~A}$ (i.e., that the claim is not 'directed to' an abstract idea) by ensuring that: a) the claim does not preempt the use of the fundamental techniques in other application domains, b) the invention as claimed is not directed to mathematical techniques but instead to the solution of a technical problem, and c) the claimed invention results in a technological improvement in the field of precision medicine (improved detection, diagnosis, monitoring, therapy optimization, etc). A claimdrafting strategy that focusses on Step 2B ("the claim as a whole amounts to significantly more than the abstract idea") faces challenges if the invention uses generic hardware (e.g., computer, smartphone, wearables, standard physiologic sensors).

The full extent of Alice's impact remains to be studied using the type of empirical methodologies previously employed to analyze
Myriad18,19,20 and Mayo21. For example, how many applications advance to an issued patent notwithstanding an initial rejection? What sorts of claim amendments assist? How long does patent prosecution take when Alice rejections are raised by examiners?

Even without this evidence, it is clear that the Alice decision affects a wide variety of algorithmic developments in precision medicine, but not all will be ultimately ineligible for patent protection. With thoughtful claim drafting and prosecution, it is possible to obtain patent protection for computerimplemented precision medicine inventions provided that they are not claimed at a high level of generality 28 and the focus of the claim is on the improvement of a technology or technical field rather than being either on the algorithm per se, or the automation of a mental process for which the computer is merely invoked as a tool.

\section{European Perspective}

Patent law in Europe is organised differently, and requires some explanation to compare its effects on precision medicine with the US. The European Patent Convention (EPC) is an international treaty, which provides harmonized rules for the grant of a bundle of European patents designated in EU Member States (and a few other countries). Like the US, patent eligibility is a requirement alongside novelty, inventive step, and disclosure. Table 1 compares the two regimes.

The guiding principle for patent eligibility in Europe is found in the decisions of the European Patent Office and the Enlarged Board of Appeal. The principle is that a patent claim is patentable if, considered as a whole, it has 'technical character'. Technical character is assessed without regard to prior art, it is not a test of technological improvement ${ }^{34}$.

This principle has substantially affected the interpretation of the 
statutory exclusions that one finds in the provisions of the EPC, namely that patents shall not be granted for: "discoveries, scientific theories, mathematical methods [...] methods for performing mental acts [...] and programs for computers $[\ldots]$ as such" (EPC Art 52(2),(3)) or methods of medical treatment and diagnostics methods practised on the human body (EPC Art 53(c)).

\section{A) Biomarkers \& Nature-Based Products}

Notwithstanding the exclusion of discoveries as such since EPC 1973, and social opposition to isolated DNA sequence patents, the EPO developed an approach supportive of biotechnological patents which was reflected in the EU Directive of $98 / 44 / \mathrm{EC}$, and formally adopted in the 2002 EPC Implementing Regulations ${ }^{35}$. Unlike the US, biological material including a DNA sequence, which is isolated from its natural environment or otherwise produced by a technical process, is eligible for patent protection ${ }^{36}$. Technical character can be conferred by a technical effect (e.g., the use of the DNA sequence in making a polypeptide or gene therapy) ${ }^{37}$ or technical processes used to identify, purify, classify, and produce it outside a living cell ${ }^{38}$.

Consistent with these rules, the EPO held that isolated DNA claims in Myriad's European BRCA patents and the Howard Florey Institutes Relaxin European patents were patent eligible in opposition proceedings in the 2000s 39,40 .

In 2017, the patentability of isolated DNA was expressly confirmed by the German Federal Court of Justice (Bundesgerichtshof), which is Germany's highest court of i.a. patent jurisdiction. This was significant, as national courts and the EPO are part of different legal orders, and the case followed the US Supreme Court decisions. The German Court stated that the mere disclosure of a DNA sequence is not patentable but the disclosure of how to create the sequence through a technical process such as isolation is, even if the process is not specifically mentioned in the claims ${ }^{41}$. The Court also clarified that in Europe and Germany, unlike in the US, there is no need to identify an inventive concept nor 'inventive surplus' to distinguish a patentable invention from an unpatentable discovery.

Comparing the U.S. and European Regimes Although patent eligible, the European system does not necessarily provide biomarkers with significantly greater patent protection than the US. For instance, a DNA sequence can lack novelty (an issue for Myriad's European BRCA patents) and will often be 'obvious' (e.g. where standard techniques of identification and isolation are used). Furthermore some EU member states have added national legislative rules which state that DNA sequence patents are limited to the uses disclosed in the patent (so-called purpose-limited protection $)^{42}$. This differs from the usual rule that a product patent covers all uses of the product provided at least one application is disclosed.

\section{B) Individual Responses \& Methods of Diagnosis: Natural Relationships \& Correlations}

Despite first appearances, the statutory exclusion in EPC Art 53(c) for methods of diagnosis practised on the human body has limited impact on precision medicine. Since it excludes only 'methods', patents may be obtained for diagnostic instruments or medical devices for use in such methods. Furthermore, the EPO has taken the somewhat surprising view that methods of diagnosis based on blood, saliva, urine, etc. are not excluded, because these methods of diagnosis do not take place on the human body, but rather in a laboratory using human tissue without the patient's 'body' being present ${ }^{43}$. The key question is whether the claimed method of in vitro diagnosis has technical character. Including a step of gathering, analyzing, or reporting data using an apparatus can suffice. For the subsequent inventive step enquiry, recognizing medical illness or abnormalities seems to count as a technical purpose ${ }^{44}$. Putting it another way, the steps involved in medical diagnosis provide a technical solution to a technical problem.

The EPO held methods of diagnosing breast cancer based on BRACA sequences were patent eligible ${ }^{45}$. More recently, in 2017, the German Bundesgerichtshof, in the receptor tyronkinase case, considered whether a method claim for detecting a specific variant of DNA was patentable. Detection can be used to diagnose leukemia. Since the detection claim included the isolated DNA claims, the Court was satisfied the method claims possess technical character ${ }^{41}$.

The European patent for NIPT, the equivalent of the US patent found invalid in Sequenom, was litigated in the UK case Illumina Inc v. Premaitha Health Plc.46 The defendants argued that the claims were invalid because they disclosed only the unpatentable discovery that paternally inherited fetal nucleic acid is detectable in pregnant women. In stark contrast to the US case, however, the Court held the claims were valid, finding they included the technical steps of creating samples for analysis and detecting nucleic acids.

Comparing the U.S. and European Regimes Methods of detection and diagnosis based on correlations and relationships are more straightforwardly eligible in Europe than the US. New methods of treatment in precision medicine are patentable in both jurisdictions, but claim drafting must be approached differently due to the exclusion in EPC Article 53(c) for methods of medical treatment. In Europe, methods of in vitro diagnosis or detection which a doctor uses in 
medical treatment are eligible. Unlike the US, it is problematic (not helpful) to direct the claim to a method of treatment.

\section{C) Algorithms and AI}

Although the EPC excludes mathematical methods (including AI methods) and programs for computers as such from patent protection (EPC Art 52(2)), many of the next generation applications in precision medicine based on some form of mathematical method, algorithm or machine-learning method are patent eligible. This is because the Art. 52(2) exclusion applies only if a claim is directed to a purely abstract mathematical method (or AI method) per se and the claim does not require any technical means (Art 52(3)).

If the claim is directed either to $a$ method involving the use of technical means (e.g. a computer) or to a device, its subject-matter has 'technical character' as a whole and is thus not excluded from eligibility under Art. 52(2). The EPO considers a patent claim to have the allimportant 'technical character' if the claim recites the use of technical means for implementation (e.g., implementing a discovery, mathematical method, mental acts or presentations of information through a general or mini-computer, smartphone, tablet, measuring device, or computer-readable storage mechanism such as a memory stick) ${ }^{47}$.

A computer-implemented claim can have 'technical character' by: 1) reciting the use of any other technical means for implementation (e.g., computer), 2) reciting an algorithm that has a technical application (the algorithm produces a technical effect by serving a technical purpose) and/or 3) the claim is directed to specific technical implementation of the mathematical method and the mathematical method is particularly adapted for that implementation (Figure 1).

All of the following pass the patent eligibility threshold if they are implemented by technical means (e.g., some kind of computer): mathematical relationships, mathematical algorithms, algorithms to collect and store data and for data visualisation, deterministic algorithms and statistical algorithms. In contrast, patent claims are likely to fail the EPC's eligibility criteria if they recite no more than the use of an artificial intelligence model (e.g., a neural network), or a computer program (in the narrow sense of a sequence of instructions to be executed by a computer).

A caveat to the principle that including a general purpose computer suffices to confer technical character arises in the case of computer programs, but these are very narrowly defined (as 'a sequence of computer-executable instructions specifying a method'), and distinguished from computerimplemented-methods ('a method being actually performed on a computer' $)^{48}$. In the case where the claim cannot be characterized as a computer-implemented method, but instead is a computer program, the caveat for eligibility is that there must be a 'further technical effect' (running a computer program on a computer does not confer technical character and is not sufficient for eligibility, notwithstanding that electrical currents are involved) ${ }^{48}$. A 'further technical effect' is a technical effect going beyond the 'normal' physical interactions between the program (software) and the computer (hardware) on which it is run.

\section{Interaction with Inventive Step}

Given that a competent draftsperson can usually present a claim as a computer-implemented method of detection or in vitro diagnosis rather than as a 'computer program' or method of medical treatment, patent eligibility (Art. 52) is not a difficult hurdle for computer-implemented precision medicine inventions in Europe. As already explained, it is relatively straightforward for a mathematical model, algorithm, or machine learning method to be eligible for patent protection; the claim simply needs to recite the use of technical means of implementation. That said, the draftsperson must also consider the inventive step inquiry. Passing this hurdle can prove challenging, if 'technical character' in the claim is achieved solely by reciting a computer (or any other technical means for its implementation).

To demonstrate an inventive step to satisfy the EPO the claim must involve a non-obvious technical solution to a technical problem ${ }^{47}$. To establish this, all features that contribute to the technical character of the invention are considered. Features that fall within Art 52(2) categories of mathematical methods, presentations of information, and computer programs can contribute to the assessment of nonobviousness ${ }^{45}$ only if they contribute to the technical character. This limits the manner in which algorithms (and other Art 52(2) features) can be the seat of the non-obvious development.

There are a variety of situations when a new algorithm contributes to the claim's 'technical character.' For example the algorithm could help produce a 'technical effect' that serves a technical purpose, either by 1) its 'application to a field of technology' and/or 2) 'by being adapted to a specific technical implementation.'

If the principles we have articulated are followed, many precision medicine applications will be deemed patent eligible subject matter in Europe (Box 2). 
Comparing the U.S. and European Regimes Despite multiple relevant legislative exclusions, European doctrine on patent eligibility of algorithms and machine learning is generous compared with the US because, generally, claim-drafting strategies can be deployed to avoid exclusion under EPC Art 52(2) 49.

Demonstrating inventive step, relative to the prior art, is the more restrictive issue for European patent protection of algorithm-based precision medicine inventions. In Europe, it is strategic to restrict an algorithm-based claim to a specific technical application or adapt it for specific technical implementation. Then the algorithm has 'technical character' and can be considered as part of the inventive step inquiry to support non-obviousness ${ }^{50}$. Notably this tip concords with the guidance above for drafting algorithm-based claims that meet US patent eligibility rules post-Alice in light of $M c \mathrm{RO}$, Enflish, and FairWarning.

\section{Conclusions}

Patent law can be likened to a pendulum, seeking an equilibrium between competing interests and tensions ${ }^{51}$. Finding a balance in the field of precision medicine is no easy feat where there are many interests: patients, various kinds of healthcare providers and health professionals, plus all manner of organizations involved in research, development and commercialization (e.g., small, large, public, private, public-private). Arriving at balanced principles is particularly difficult when patent law principles must not discriminate against technologies but accommodate also articles of manufacture, machines, and compositions based inventions ${ }^{52}$. So it is not surprising that the law on patent eligibility oscillates, nor that the patenting of precision medicine is complex and uncertain.

The difficulty with a swinging pendulum in law is that, unlike a

\section{Box 2 Precision Medicine Examples Meeting European Subject Matter Eligibility Requirements}

As discussed in this article, an Art 52(2) type feature can contribute to technical character through 'technical application' if it produces a specific technical effect for a technical purpose. The claim must be functionally limited to the technical purpose, either expressly or implicitly. Some examples related to precision medicine involving mathematical methods and algorithms include (1) providing a genotype estimate based on an analysis of DNA samples together with a confidence interval of reliability, and (2) providing a medical diagnosis by an automated system that processes physiological measurements. Examples in the case of artificial intelligence and machine learning include (3) the use of a neural network in a heart-monitoring apparatus for the purpose of identifying irregular heartbeats, and (4) the use of machine learning in a method to classify types of irregular heartbeats, where generating the training set and training the classifier support a technical purpose (EPO November 2018 Examination Guidance). An example in the case of presentations of information is (5) presenting a visual stimulus to a person for the purpose of producing in that person a physiological reaction (e.g. involuntary eye gaze) which can be measured in the context of assessing a medical condition (e.g. brain damage, or vision impairment). Additionally, an Art 52(2) type feature can contribute to technical character through 'technical implementation' if the claim states the Art 52(2) type feature is adapted to a specific technical implementation. For instance, if an algorithm is adapted by technical considerations to the internal functioning of a computer. physical pendulum, there is no set path or timing. In the aftermath of Mayo, Myriad, and Alice, the legal protection for precision medicine inventions faced a high degree of uncertainty, as the evolving doctrine of patent eligibility was reformulated. We are still witnessing the effects of that uncertainty, just as we begin to see signs that a new era is emerging. Post-Vanda and with Andrei Iancu taking over from Michelle Lee as the Director of the USPTO, and with patent attorneys learning new claiming-drafting approaches, the restrictive and uncertain patentability of biomarkers, medical correlations and algorithms is easing off. In this era, other patent doctrines will probably come to the fore as key policy levers (e.g., non-obviousness). But how, when, and to what degree these developments will take shape remains uncertain.

In Europe, there has also been some swinging of the proverbial pendulum for precision medicine and patentable subject matter. The swing has not been as wide nor as forceful as in the US, thus the law has felt more stable; but swing it does, nevertheless. Notably the EPC and US are swinging to a different beat. Presently the EPC law on patentable subject matter is relatively generous for precision medicine in biomarkers, correlations, in vitro methods of detection and diagnosis, and algorithms ${ }^{53}$.

A divergence between US and European laws pertains to the patent subject-matter eligibility of naturebased biomarkers. In Europe, biomarkers are patent-eligible even if merely isolated from their natural environment; whereas in the US biomarkers must be markedly different from naturally-occurring products or the claims must include significantly more (which tends to narrow the claim). In contrast, we seem to be entering a period of increasing convergence with respect to patentability of applied algorithms, mathematical methods (including AI), computer programs, methods of treatment based on biomarkers and diagnosis (provided one considers the combined effect of eligibility and non-obviousness inquiries). This convergence is particularly noticeable following $M_{c R O}{ }^{31}$, Enfish ${ }^{32}$, and $V a n d a^{25}$ as well as recent EPO and USPTO Examination Guidelines. 
For methods of detection, diagnosis and treatment, there are still some cross-jurisdictional differences, but convergence is afoot. In Europe, methods of detection and in vitro diagnosis are generally patent eligible; a competent draftsperson can find language that achieves technical character. In the US, these methods are still affected by the two step Mayo/Alice test, particularly methods of diagnosis. In response, and post-Vanda, methods of medical treatment are likely to become the claims de jour for medical correlations and relationships. Whereas in Europe, methods of medical treatment cannot be claimed per se but with appropriate claimdrafting could be protected as applications of a new method of diagnosis, or in the form of a medical kit or device.

As an IP intensive field, a reasonable degree of legal certainty is needed in order to promote research, technology-transfer, investment, and innovation. These legal principles, with their cross-Atlantic similarities and differences, and swinging natures, have considerable significance for the future of precision medicine.

1. Hogarth, S. Personalized Medicine - A Typology Briefing for CADTH. (CADTH, Ottawa, 2016).

2. Global Precision Medicine Market to Reach $\$ 141.70$ Billion by 2026, Reports BIS Research. in BIS Research (2017).

3. BEST (Biomarkers, EndpointS, and other Tools Resource. (FDA-NIH Biomarker Working Group, 2016).

$4 . \quad$ Ioannidis, J.P.A. \& Bossuyt, P.M.M. Waste, Leaks, and Failures in the Biomarker Pipeline. Clinical Chemistry 63, 963-972 (2017).

5. Breastcancer.org. Oncotype DX Test. 6. Horak, F.B. \& Mancini, M. Objective Biomarkers of Balance and Gait for Parkinson's Disease using Body-worn Sensors. Movement Disorders 28, 1544-1551 (2013).

$7 . \quad$ Price, W.N. Black-Box Medicine. Harvard Joutnal of Law \& Technology 28, 419-467 (2015).
8. Mayo Collaborative Services v. Prometheus Laboratories, Inc. in S. Ct., Vol. 1321289 (Supreme Court, 2012).

9. Association for Molecular Pathology v.

Myriad Genetics, Inc. in S. Ct., Vol. 1332107

(Supreme Court, 2013).

10. Sherkow, J.S. \& Greely, H.T. The History

of Patenting Genetic Material. Annual Review of

Genetics 49, 161-182 (2015).

11. Holman, C.M. The Mayo Framework is Bad for Your Health. George Mason Law Review 23, 901-940 (2016)

12. Schwartz, R.M. \& Minssen, T. Life after Myriad: The Uncertain Future of Patenting Biomedica Innovation and Personalised Medicine in an

International Context. Intellectual Property Quarterly 3, 189-241 (2015).

13. Alice Corp. v. CLS Bank International. in

S. Ct., Vol. 1342347 (Supreme Court, 2014).

14. Bilski v Kappos. in S. Ct., Vol. 1303218

(Supreme Court, 2010).

15. Diamond v. Diehr. in S. Ct., Vol. 1011048

(Supreme Court, 1981).

16. In re Abele and Marshall. in F.2d, Vol. 684

902 (United States Court of Customs and Patent Appeals)

17. 2019 Revised Patent Subject Matter

Eligibility Guidance. Federal Register. Vol. 84 (2019).

18. Aboy, M., Liddell, K., Liddicoat, J. \&

Crespo, C. Myriad's impact on gene patents. Nature

Biotechnology 34, 1119-1123 (2016).

19. Aboy, M., Liddicoat, J., Liddell, K.,

Jordan, M. \& Crespo, C. After Myriad, what makes a gene patent claim 'markedly different' from nature? Nature Biotechnology 35, 820-825 (2017).

20. Aboy, M., Crespo, C., Liddell, K.,

Liddicoat, J. \& Jordan, M. Was the Myriad decision a

'surgical strike' on isolated DNA patents, or does it

have wider impacts? Nature Biotechnology 36,

1146-1149 (2018)

21. Aboy, M., Crespo, C., Liddell, K.,

Minssen, T. \& Liddicoat, J. After six years, what has been Mayo's impact on patent applications related to biotech, diagnostics, and personalized medicine? Nature Biotechnology 37(2019).

$22 . \quad$ Gold, R.E., Cook-Deegan, R. \& Bubela, T. AMP v. Myriad: A Surgical Strike on Blockbuster Business Models. Science Translational Medicine 5(2013).

23. Ariosa Diagnostics, Inc. v. Sequenom, inc. in F.3d, Vol. 5881371 (Court of Appeals for the Federal Circuit, 2015)

24. Norton, M.E., et al. Cell-free DNA Analysis for Noninvasive Examination of Trisomy. The New England Journal of Medicine 372, 1589-1597 (2015).

25. Vanda Pharmaceuticals Inc., v. West-Ward Pharmaceuticals International Ltd. in F.3d, Vol. 887 1117 (United States Court of Appeals for the Federal Circuit, 2018).

26. Fox, J.L. Industry reels as Prometheus falls and Myriad faces further reviews. Nature Biotechnology 30, 373-374 (2012).

27. Malecek, M.J., Barnes, R., Goldstein, T.C \& Citron, E.F. On Petition for a Writ of Certiorari to the United States Court of Appeals for the Federal Circuit. (2016).

28. In re Grams. in F.2d, Vol. 888835 (Federal Circuit, 1989).

29. Gottschalk v. Benson. in S. Ct., Vol. 93

253 (Supreme Court, 1972).

30. Parker v. Flook. in S. Ct., Vol. 982522

(Supreme Court, 1978)

31. McRO, Inc. v. Bandai Namco Games

America Inc. in F.3d, Vol. 8371299 (Federal Circuit, 2016).

32. Enfish, LLC v. Microsoft Corp. in F.3d,

Vol. 8221327 (Federal Circuit, 2016).

33. Fairwarning IP, LLC v. Iatric Systems, Inc.

in F.3d, Vol. 8391089 (Federal Circuit, 2016).

34. EPO Guidelines, G II, 2 Examination

practice. (1 Nov 2018,).

35. EPC Implementing Regulations. Official

Journal EPO. Decision of the Administrative Council of 12 December 2002 adopting the Implementing Regulations to the European Patent Convention 2000. 36. $\quad$ EPC Implementing Rules, ss.27(a) and $29(2)$

37. EPO Guidelines, G-II, 3.1 Exclusion of discoveries. (1 Nov 2018).

38. EPO Guidelines, G-II, 5.2 (exclusions and exceptions for biotechnological inventions). (1 Nov 2018).

$39 . \quad$ T0272/95 Relaxin/Howard Florey

Institute. (EPO Boards of Appeal, 2002).

40. T 0666/05 (Mutation/University of Utah). (EPO Boards of Appeal, 2008).

41. Case No. X ZR 141/13. (German Federal Court of Justice (Bundesgerichtshof), 2016).

42. Cole, P. Patenatbility of Genes: A

European Union Perspective. Cold Spring Harbor

Perspectives in Medicine 5, 1-12 (2015).

43. EPO Guidelines, G-II, 4.2 Exclusion of diagnostic methods. (1 Nov 2018).

44. $\quad$ EPO Guidelines, G-II, 3.3 Exclusion of mathematical methods. (1 Nov 2018).

45. Matthijs, G., Huys, I., Van Overwalle, G. \& Stoppa-Lyonnet, D. The European BRCA paten oppositions and appeals: coloring inside the lines.

Nature Biotechnology 31, 704 (2013).

46. Illumina, Inc. v. Premaitha Health, Plc. in

EWHC, Vol. 2930 (Chancery Division (Patents Court), 2017).

47. EPO Guidelines, G-II, 3.3 Exclusion of mathematical methods and and 3.51 (schemes, rules and methods for performing mental acts), and 3.77 (presentations of information). (1 Nov 2018).

48. EPO Guidelines, G-II, 3.6 Exclusion of computer programs. (1 Nov 2018).

49. Minssen, T. \& Pierce, J. Big Data and Intellectual Property Rights in the Health and Life

Sciences. in Big Data, Health Law, and Bioethics (eds. Cohen, I.G., Fernandez Lynch, H., Vayena, E. \& Gasser, U.) (Cambridge University Press, Cambridge, UK, 2018).

50. $\quad$ EPO Guidelines, G-VII, 5.4 (Claims comprising technical and non-technical features). (1 Nov 2018).

51. Minssen, T. Patenting Human Genes in Europe - and how it compares to the US and Australia. in Research Handbook on Intellectual Property and the Life Sciences (eds. Matthews, D. \& Zech, H.) 26-39 (Edward Elgar Publishing, Chelthenham, UK, 2017). 52. TRIPS. Art 27(1).

53. Minssen, T. \& Schwartz, R.M. Separating sheep from goats: A European view on the patent eligibility of biomedical diagnostic methods. Journal of Law and the Biosciences 3, 365-372 (2016). 